\title{
Modulation of BTEX Bio-Remedial Activity by Molecular Triggering from Facultative Anaerobic Activity
}

\author{
Chang HD ${ }^{2 *}$, Wan $\mathrm{XY}^{1}$ and Huang HI${ }^{1}$ \\ ${ }^{1}$ Institute of Safety, Health and Environmental Engineering of Ming Chi University of \\ Technology, Taiwan \\ ${ }^{2}$ Department of Safety, Health and Environmental Engineering of Ming Chi University \\ of Technology, Taiwan
}

\section{Research Article \\ Volume 4 Issue 2}

Received Date: June 17, 2019

Published Date: June 27, 2019

DOI: $10.23880 /$ oajmb-16000147

*Corresponding author: Hsiao-dao Chang, Department of Safety, Health and Environmental Engineering of Ming Chi University of Technology, 84 Gungjuan Rd., Taishan Dist. New Taipei City 24301, Taiwan, Tel: +886-2-2908-9899 \# 4659; Email: dao6@mail.mcut.edu.tw

\section{Abstract}

BTEX (Benzene, Toluene, Ethylbenzene, Xylene) is widely reside in fuel and painting process, such as industrial metal painting. Due to their volatile character, it is easily emitted and recalcitrant in disintegration through aromatic property. These vapor inhaled and slow corruption the lipid membrane of the lungs tissue. Benzene and derivatives are thus more mutagenic and carcinogenic evaluated. The leakage of oil and spoil the soil and groundwater which arouse public concern about health respect. Therefore, it is crucial to develop high-efficiency of pollutant transformation, with aims to instant treatment of their toxicity or start remediation process. This study had screened several active isolates from bio-fixed biofilms consortia were carried. The investigation concerns the supplement of electronic molecules for the remediation effect of BTEX were tried and the cultivation status of facultative anaerobic state were addressed. In highlight of finding with high activity consortium was enriched from humic acid eluted from compost of kitchen waste, add additional 400 mg/L BTEX compound over almost one year. Active isolate were compared by using different carbon source as electron donors with $31.2 \mu \mathrm{M}$ substrate concentration. After the basal carbon source as humic acid and molasses was extra added and compared, remedial activity of the strain with 3-3>3-1>2-6 were compared. As a second level analysis, the remedial effects shown: methanol>glucose>indole acetic acid>indole, indicated that the electromotive force might influenced by the grafting carbon chain, the length of carbon grafting, the influence of reducer as ferrous ions in medium, also the free benzoic compound interacted, dynamic directing the direction of electron flux from humic acid or molasses, overall, humic acid, generally less conversion, believed only support electron mediation in other reaction. While molasses, macromolecular and exhibits a reducing power with glucose and methanol. However, it causes invalid electronic flux into aromatic conversion but competitively switch to oxidative respiration. Resulted an invalid co-metabolism. The significant of remedial effect by grafting aromatics and soluble humic acid were demonstrated in this report. 
Keywords: BTEX; Bio-Immobilization; Toxicant Conversion; Co-Metabolism; Redox Potential

\section{Introduction}

BTEX (Benzene, toluene, ethylbenzene, xylene) is also easy dissolved into lipid tissue eg. lung, for its hydrophobic nature; It was recalcitrant for metabolic degradation because of aromatic structure. Those transportation into ecological multi-media as soil, ground water and sewage bio-solid, which became enormous environmental issue through vast dissemination and cause potentially physiological distress, as instant discomfort, and even carcinogen ascertained pertaining benzene and ethyl benzene [1]. In the treatment by environmental engineering concern, the application of bioreactor for effective remediation purpose, the core technology debated was increase the reactive microorganism retainable in the reactor, thus increasing degradation or natural attenuated though effective consortia retained as designed. The bountiful food chain as hig of many kinds, with organic or inorganic forms of nutrient, enriched the effective microorganism for attack C6 moiety of benzene, many report discussed cometabolic role pertaining to similar structure, as increasing degradation by benzoic acid [2]. Increase electron flux by specific substrate, as methane [3], methanol [4], acetate [5]. Oxidation key enzyme as dioxygenase was evident for attack specific site in the benzene derivatives [6], also pertaining to oxidative pretreatment [7]. Presently, we are more focusing on the revealing of conversion through relative molecule structure for possible nucleophilic attack, which ravel another metabolic route for anaerobic remedial treatment for aromatic compound. Since biological treatment should integrated with chemical and physic pretreated for gaining more efficient way for total treatment in the future. The present report deal with chemical supplement for formulation, especially focuses on the possible modulation concern surface nature and modulated reaction [8,9]. The co-metabolism toward aromatic of toxic chemical were originate from double bonding of substrate which derive higher and shorter time consumed for raising degradation activity. The report finally deduced that from hydroxyl to carbonyl was the indispensable intermediate step for conversion. Thus, electronic media as salicylic acid set the important role in mode of action [10]. It was in this way of finding intermediate compound for knowing metabolic chain.
This study explores the carbon electronic media and molecular supplement for phase cultivating and effects to the degradations of BTEX under facultative anaerobic conditions [11]. Humic acid formed from agricultural waste compost, which to be the smallest humus debris as single bonding of $\mathrm{C} 6$, In contrast. Odor compound as indole in the feces, indole tri-acetic acid in the rhizosphere environment which produce strong regulatory role for plant growth [12], the combination of these pair could be a set modulation for initiate or elicit the conversion as intimately as catalyst $[13,14]$. The relationship between the metabolism and intermediate might give ideas for enhance biological treatment and process to efficient trigger molecular regulation in the future.

\section{Materials and Methods}

\section{Immobilization of poisonous microorganisms}

The biofilm was made of polyvinyl alcohol as a porous carrier, and a 1:1 matrix prepared by a $1200 \mathrm{~g} / \mathrm{LBTEX}$ solution and a kitchen waste-soluble substance was used to form a biofilm by hydraulic retention for 10 days. When the bio-immobilized filter bed's toxic microbial system reaches equilibrium, the system sludge is produced [15]. The sludge is cultured and domesticated using long-term strains, and the isolates after serial dilution have nine species. The strain 3-1, the strain 3-3a and the strain 2-6a were selected for toxicity conversion experiments (Figure 1).

There are three dominant bacteria groups selected for screening. The minimum nutrient salt medium used in the screening bacteria contains $5 \mathrm{mg}$ of boric acid, $0.3 \mathrm{~g}$ of magnesium sulfate, $0.5 \mathrm{mg}$ of potassium iodide, $1 \mathrm{~g}$ of ammonium sulfate, $5 \mathrm{mg}$ of ferrous sulfate, $0.3 \mathrm{~g}$ of sodium sulfide, $0.3 \mathrm{~g}$ of dipotassium hydrogen phosphate, and sulfuric acid per liter of DI water, calcium $0.5 \mathrm{~g}$, zinc sulfate $1 \mathrm{mg}$, brown sugar $0.5 \mathrm{~g}$, Primex Marine Peptone $0.5 \mathrm{ml}$ and Vitamin B group (Centrum) $0.25 \mathrm{~g}$. The medium was first sterilized by pressure using $1.2 \mathrm{~kg} / \mathrm{cm} 2$ for 20 minutes, and $400 \mathrm{mg} / \mathrm{l}$ of each BTEX ingredient was added during the culture, thereby cultivating the medium of metabolically toxic bacteria [16] (Table 1). 


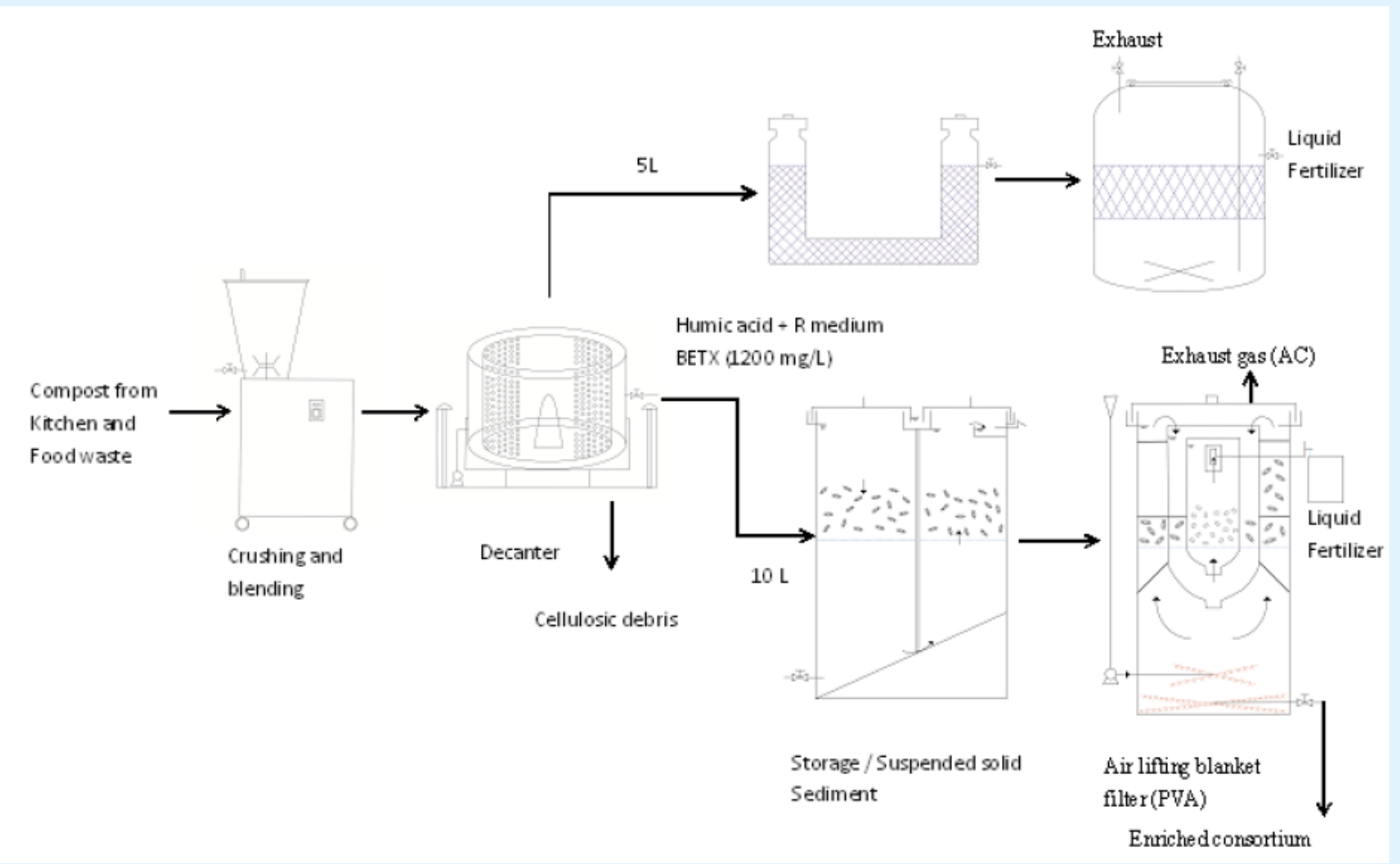

Figure 1: Set-up of air lifting facultative anaerobic system for remediation of BTEX solution.

There are three dominant bacteria groups selected for screening. The minimum nutrient salt medium used in the screening bacteria contains $5 \mathrm{mg}$ of boric acid, $0.3 \mathrm{~g}$ of magnesium sulfate, $0.5 \mathrm{mg}$ of potassium iodide, $1 \mathrm{~g}$ of ammonium sulfate, $5 \mathrm{mg}$ of ferrous sulfate, $0.3 \mathrm{~g}$ of sodium sulfide, $0.3 \mathrm{~g}$ of dipotassium hydrogen phosphate, and sulfuric acid per liter of DI water, calcium $0.5 \mathrm{~g}$, zinc sulfate $1 \mathrm{mg}$, brown sugar $0.5 \mathrm{~g}$, Primex Marine Peptone $0.5 \mathrm{ml}$ and Vitamin B group (Centrum) $0.25 \mathrm{~g}$. The medium was first sterilized by pressure using $1.2 \mathrm{~kg} / \mathrm{cm} 2$ for 20 minutes, and $400 \mathrm{mg} / \mathrm{l}$ of each BTEX ingredient was added during the culture, thereby cultivating the medium of metabolically toxic bacteria [16] (Table 1).

\begin{tabular}{|c|c|c|c|}
\hline $\begin{array}{c}\text { Isolate } \\
\text { Number/Origin }\end{array}$ & $\begin{array}{c}\text { Identification } \\
\text { Method }\end{array}$ & Isolate Name & $\begin{array}{c}\text { Protease Specific Activity }(\boldsymbol{\mu m o l e} / \mathbf{m g} \\
\text { protein/min) }\end{array}$ \\
\hline $3-\mathrm{Feb}$ & $\begin{array}{c}16 \mathrm{~S} \text { rDNA } \\
\text { sequencing }\end{array}$ & Bacillus subtilis sH-3 & 0.244 \\
\hline $6-\mathrm{Feb}$ & $\begin{array}{c}16 \mathrm{~S} \text { rDNA } \\
\text { sequencing }\end{array}$ & Lysimnibacillus maroides sCS-26 & 0.261 \\
\hline 1-Mar & $\begin{array}{c}16 \mathrm{~S} \text { rDNA } \\
\text { sequencing }\end{array}$ & Bacillus cereus s133 & 0.222 \\
\hline $5-\mathrm{Mar}$ & $\begin{array}{c}16 \mathrm{~S} \text { rDNA } \\
\text { sequencing }\end{array}$ & Bacillus thuringiensis sS3-3 & 0.222 \\
\hline $7-M a r$ & $\begin{array}{c}16 \mathrm{~S} \text { rDNA } \\
\text { sequencing }\end{array}$ & Bacillus cereus nZ2-1 & 0.197 \\
\hline
\end{tabular}

Table 1: Selection of enrichment isolates by limited melanoid sugars in acclimation biofilter reactor. 


\section{Open Access Journal of Microbiology \& Biotechnology}

\section{Experimental Equipment}

Includes micro scales, constant temperature incubators, aseptic workstations, spectrophotometers, VOC purge and trap apparatus (OI-Analytical, 4560, sample concentrator), gas chromatograph/flame ion detector (Agilent Technology 6850 net GC) [17].

\section{Co-Metabolites and Electronic Media Substances}

The co-metabolites used in the analysis include $<5 \mathrm{~nm}$ humic acid monomer and macromolecular humic acid molasses as metabolized carbohydrates; the application of electronic media substances include formic acid, methanol, physiologically active species - indole, indole triacetate and the like. Also, the effect of glucose should be controlled [13].

\section{Quantitative Line Production}

Take $400 \mathrm{mg}$ of each of toluene, ethylbenzene and xylene in the culture solution to prepare a test concentration of $-1200 \mathrm{mg} / \mathrm{L}$ as a sample. Then prepare $80 \mathrm{ml}$ of sterilized medium and dilute to a total concentration of $75 \mathrm{mg} / \mathrm{L}, 150 \mathrm{mg} / \mathrm{L}, 300 \mathrm{mg} / \mathrm{L}, 600$ $\mathrm{mg} / \mathrm{L}$, and $1200 \mathrm{mg} / \mathrm{L}$. After 30 minutes of shaking, the samples were diluted five times in equilibrium and subjected to VOC purge and trap concentration, and analyzed using a gas chromatograph/flame ion detector. Next, the concentration matrix is used to perform concentration matrix regression, thereby preparing a calibration curve and performing sample concentration detection.

\section{Identification of Strains}

The selected strains were subjected to PCR technology by Protech Technology Enterprise Co., Ltd to increase the $16 \mathrm{~S}$ rDNA sequence (about $200 \mathrm{bp}$ ). After sequencing, the NCB1 database is compared to identify the strain identity (determined to the generic name) [18]. The results of the identification indicated that three strains were closest to B. T. cactus. The strain $3-1$, the strain $3-3 a$, and the strain 2-6a were used as test strains.

\section{Strain Metabolism Fermentation Experiment}

The eutrophic electron donors were explored using humic acid and molasses, and glucose, methanol, formic acid, indole and indole triacetate were again explored as auxiliary electronic media effects. $80 \mathrm{ml}$ of BTEX and BTEX-diluted co-metabolism (about turbidity A520 of about 0.6) were added to the flask. After sterilization, $1 \mathrm{ml}$ of the bacterial suspension was added. Next, the shaking culture was sampled at 0 hours, 2 hours, 4 hours, 1 day, 2 days, 3 days, 4 days, 5 days, 7 days, 9 days, etc. to analyze the volatile components of the fermentation broth by GCFID. In this way, the peak integrated area of the spectrum is analyzed, and the content of BTEX components and the degradation efficiency are calculated according to the calibration curve.

\section{Analysis of the Nature of the Fermented Sample}

The initial and final sample properties of the fermentation include analysis of $\mathrm{pH}$, redox potential (ORP), A605 absorbance, and GC-FID.

\section{Results and Discussion}

\section{Effect of Electronic Donor and Regulators for Microbies 3-1 Degradation of BTEX}

The active strain 3-1 - Bacillus cereus, known the hydrocarbon as acclimated from BTEX with reactivity of remedial BTEX in $\mathrm{Fe}++\mathrm{R}$ medium. In attempting to first 4 hours cultivation showed high BTEX. Removal effected especially as xylene, toluene by the grafting role toward side chain. Due to the chromogen humic acid with surface functional and exerted the adsorption and desorption behavior also retained their cyclic structure. The result shown that after three hours incubation and compared to the control series, the brownish humic acid or molasses series raised then toxicant concentration related desorption (Figure 2a). In which Ethylbenzene is similar to toluene, seems a level of reduced rate of desorption due to its surface property and more biological transforming relevant (Figures 2d, 2e). But for xylene, although it has a lowest solubility, so most of it may exist and pruned to be micelle absorbed and easily interact with the cells. Therefore, the remedial result was higher removal ratio throughout culture period.

In attempting to assess the chrome sugar as molasses had surface hydroxyl moiety for remedial interactions; result showed a fluctuation react. After adding the electron donor methanol for four hours, the molasses fermentation in the four-day culture period showed a fluctuating result, indicating although there were more dissolved substances but might not in the same phase arranged layer for effective remediation (Figure 2c). Contrary, when humic acid was added to the series of less soluble as ethylbenzene, the effect of humic acid was obvious than over the control group which could be enhanced remedial effect through fermentative metabolism by effective electron supply and also mediator for linkage of reaction chain. Decompose after four days of fermentation in mediation - humic acid, nearly completely (Figure $2 \mathrm{~b}$ ). 


\section{Open Access Journal of Microbiology \& Biotechnology}
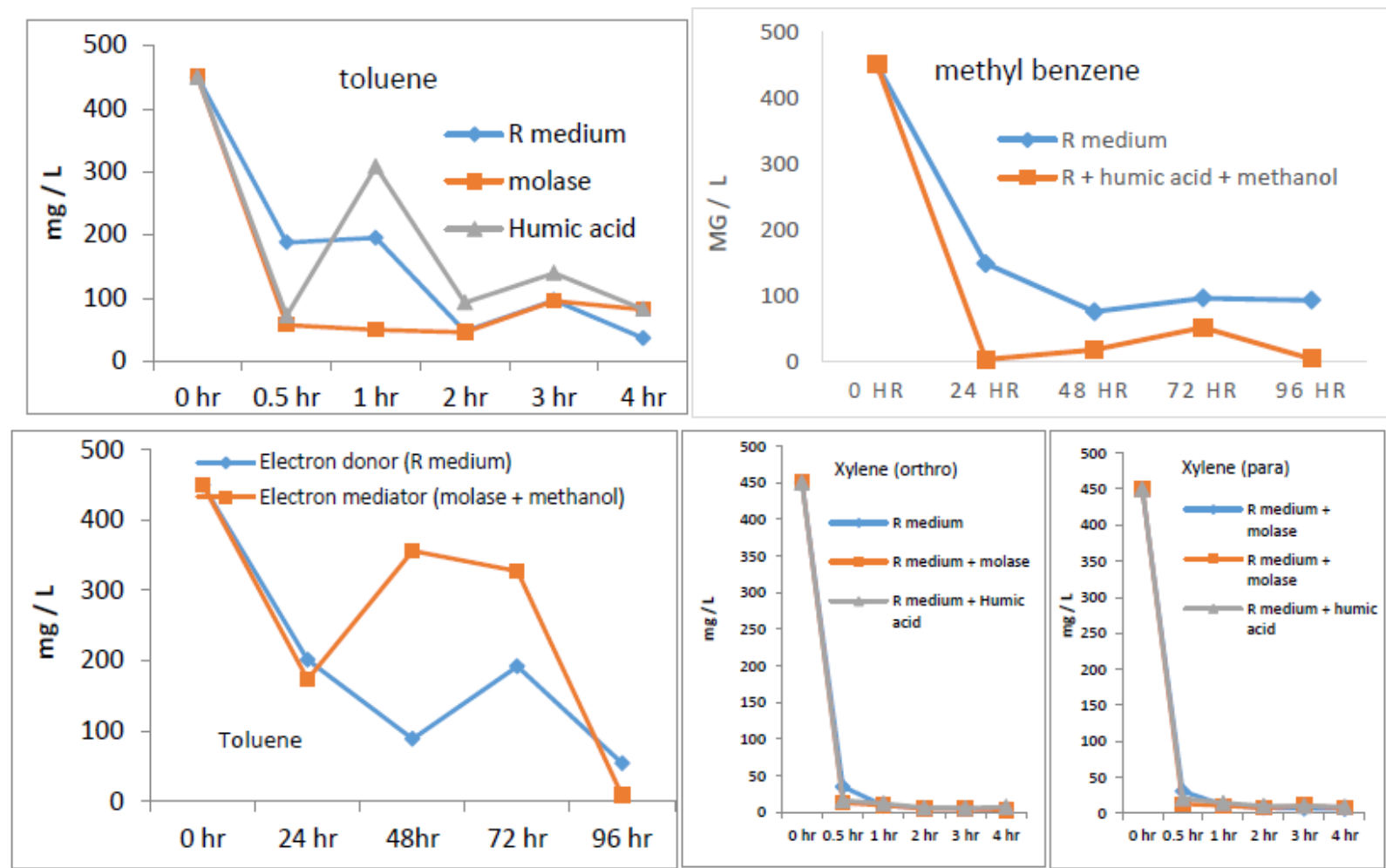

Figure 2: Effect of electronic suppliers on the degradation of active bacteria BTEX: Effect of electronic donors with mediators for the microbe 3-1 on the BTEX.

The surface structure of some natural chromogenic molecule had extraordinary anti-oxidative activity, eg. anthocyanins, for having surface hydroxyl, static negative potential toward others [19], like donate reducing power. While long hydro carbon chain have donation electron away from the skeleton, which prone to nucleophilic attack by free radicle. Based on this points of view, IAA would probably to meet the criteria for remediation; also many microorganisms (phytobiotics, including pathogenic bacteria) of rhizosphere have the ability to synthesize IAA, which affects balance of hormones in plants [20] as well as remedial activity. Reports had plant growth promoting rhizo-bacteria (PGPR) and Trichoderma biological control fungi have the potential to promote plant growth due to IAA and derivatives. Agrobacterium tumefaciens also uses IAA as a virulence-induced root cancer. Therefore, the rhizosphere microbial developmental conditions as well as growth hormone degradative had great influence on the attenuation of the surrounding condition as formation of a facultative anaerobic, high reducing environment. The experiment presently showed that the active strain 3 - 1 decrease the remedial effect on the supplement of IAA (Figure 3a), the effect was notice as affect the bacterial growth. In comparison molasses had more adverse effects, may due to the complex hydrocarbon property ease for primary metabolism not conductive to the degradation of benzene ring structure (Figure $3 \mathrm{~b}$ ), possibly related second metabolism other low molecule or short-chain fatty acid, hydrogen protons, etc. in the surface that intimately related to electron supply potential. In contrast, humic acid improves the removal performance of toluene and ethylbenzene because the molecule had its unit cone of ring structure, and construct amphipathic group as donor or accepter for mediation electric attraction. Therefore, it can improve the degradation of toluene and ethylbenzene in the original medium (Figure 3c). Even within 4 hours of fermentation, a stable reaction can be exhibited in a state, even the cells are not proliferated and physiological role still driven the remedial are metabolic active. Therefore, in terms of the degradation of benzene structure, the role of electrophilic substitution due to the electrons potential pushed by the alkyl substituent. 

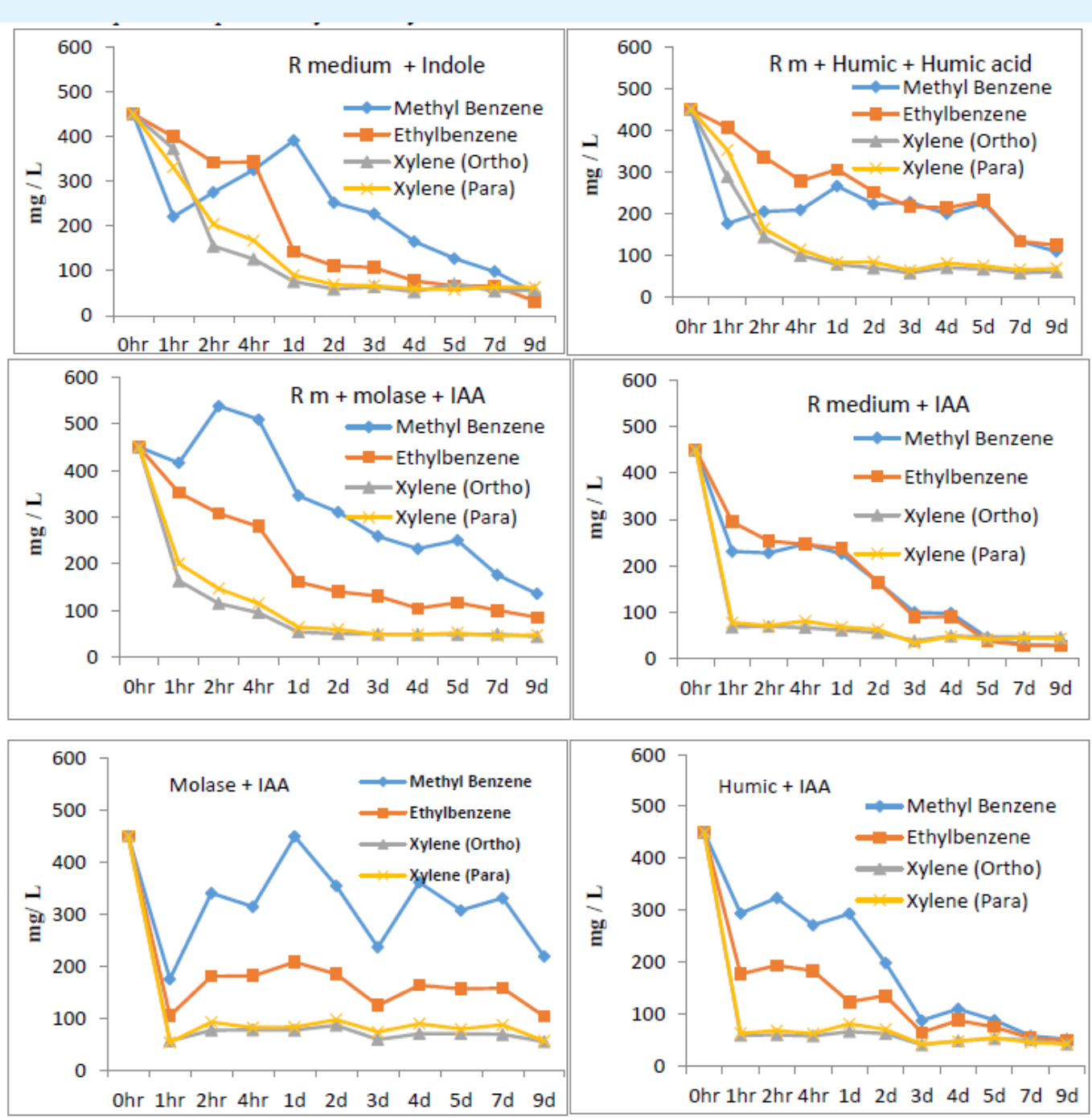

Cultivation time

Figure 3: Effect of electronic media on the degradation of active bacteria 3-1 BTEX.

\section{Proliferation Curve of Active Bacillus 3-1 for BTEX Remedial Growth}

With the implementation of donor as glucose for growth, humic acid, slow utilization for utilization for fermentation, which role of electronic media. Relationship between strains and indole, IAA were selected for electronic media, the effect of supporting logarithmic growth were assessed in hours of fermentation. Results indicate the glucose had a growth cycle over 60 hours which to be the maximum growth rate obtained (Figure $4 \mathrm{~b})$. The molasses series delayed the growth period to 72 hours, and the control group, the humic acid group had entered the death period at this time. As the BTEX concentration, the concentration was higher in these experimental series. It was also worth mentioned that the higher concentration of molasses series in period 2 hours before the addition of IAA rise its concentration shown. This was reasonably believed the strain lacked adaptation, and had decreased population at that period. After the fermentation reached 4 hours, cell of strain showed steadily growth in humic acid. Growth showed a trend between 48 and 72 hours, and BTEX concentration appeared lowered (Figure 4c). 


\section{Open Access Journal of Microbiology \& Biotechnology}
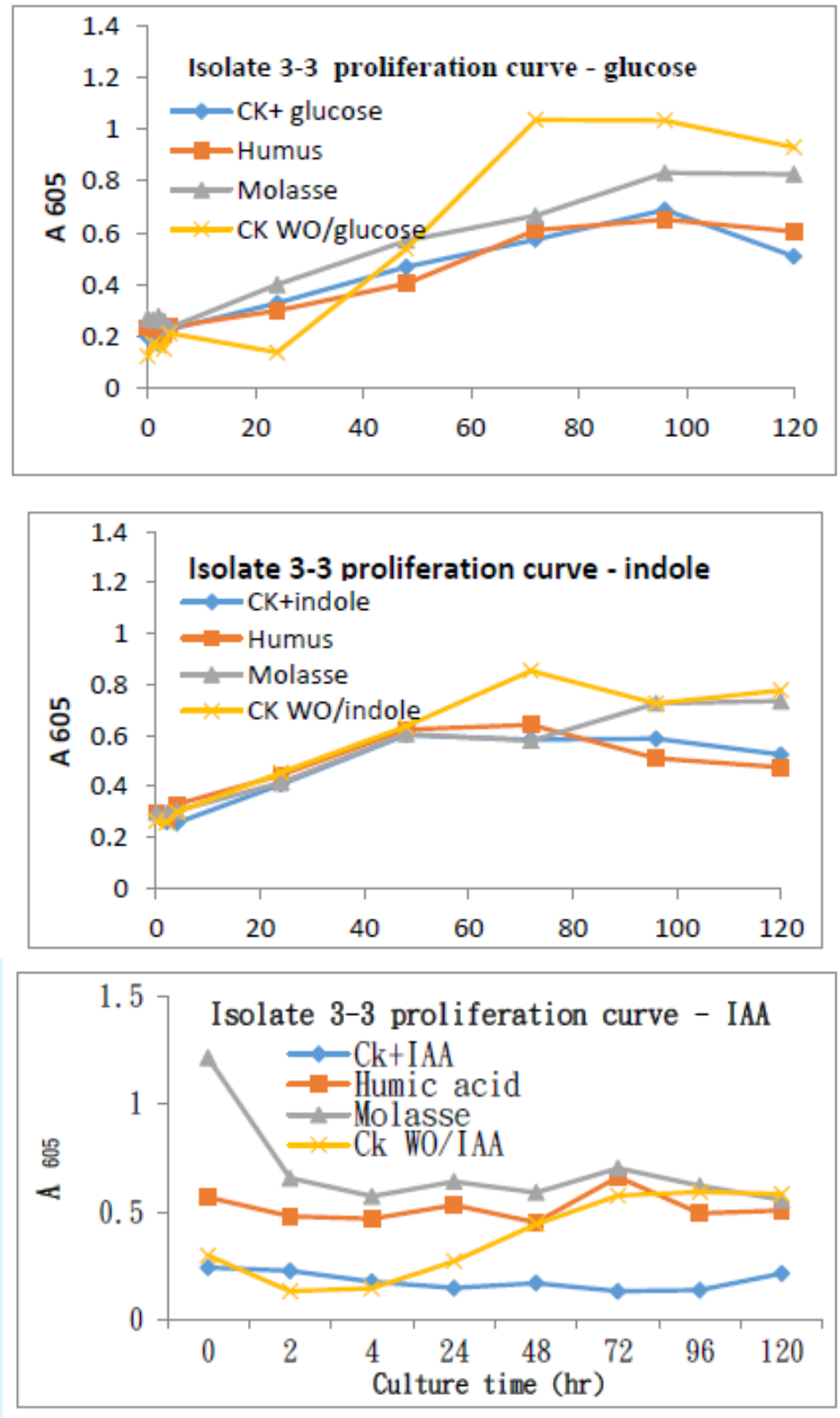

Figure 4: Effect of bacterial growth of various electronic suppliers and electronic media substances.

It is rational to take BTEX as a De Naple in a high remedial concentration. To formulate a proper way of dealing in homogenous state by effective contacting and reaction were crucial. The incorporation of multi-layer of colloid was so far accepted for both chemical and biological remediation. This paper demonstrated that different properties of hydrocarbon, electron mediator, and biological activator had all their value over simple reaction as cell catalysis of reaction; while more intimately related to consider electron flux, also their direction ox-redo reaction in the colloid interface.

It is important to have the cell catalyst maintain is high activity in the remediation process. The measuring of concentration during the suppressive of IAA on cell growth can be diminished by humic acid, which means those surfaces are affiliated due to the proximity of the molecule, which reduces the effect of alkyl group on the 


\section{Open Access Journal of Microbiology \& Biotechnology}

cell wall $[21,22]$. Results also show that the ring structure cell as molasses does not effectively on the degradation ability about the BTEX [23], while other like cultivation of different donor and regulator which revealed that small molecule humic acid, diphenyl ring indole, can effectively improve the treatment [24]. since IAA affects cell proliferation but cell still catalytically degrade before mid-log phase [25]. Particularly, the first day of the latent-period and from second to third days of medium $\log$ phase, the degradation of the BTEX is active, indicating that the microorganism can exert primary and secondary metabolism and undergo degradation as reported either [26-28].

\section{Conclusion}

(1) The BTEX-degraded active strain establishes the best electron supplier and electronic media substance assistance, and can obtain the effect of determining the reaction rate within 5-7 days of culture.

(2) The cactus strain cultivated by immobilized biofilm has the activity of facultative anaerobic degradation of BTEX. Benzene ring derivatives such as soluble humic acid and macromolecular molasses have certain conditions that promote mediation. Electron suppliers such as methanol perform at 4 hours, and glucose exhibits growth activity, which is thermodynamically superior or related to cell growth ( 2 to 4 days).

(3) The activity of electronic media substances such as IAA can show significant degradation in the first 2 hours and poor performance in 2 to 4 days. Indole has a significant boosting effect. Both of them cooperate with dissolved humic acid to promote the effect. The indole has a guiding role for the reaction site, while the indole triacetate effectively exerts a nongrowth reaction, such as secondary metabolism.

\section{References}

1. Xiong F, Li Q, Zhou B, Huang J, Liang G, Zhang L, et al. (2016) Oxidative stress and genotoxicity of long-term occupational exposure to low levels of BTEX in gas station workers. Internal J Environ Res Pub Health 13(12): 1212

2. Kim SJ, Yang PY (2005) Combined removal of highstrength organics and nitrogen using two stage entrapped mixed microbial cell (2sEMMC). Process. J Ind Eng Chem 11: 954-951.
3. Feisthauer S, Seidel M, Bombach P, Traube S, Knöller $\mathrm{K}$, et al. (2012) Characterization of the relationship between microbial degradation processes at a hydrocarbon contaminated site using isotopic methods. J Contam Hydrol 133: 17-29.

4. Galperin MY (2007) Some bacteria degrade explosives, others prefer boiling methanol. Environ Microbiol 9(12): 2905-2910.

5. Spormann AM, Widdel F (2000) Metabolism of alkylbenes, alkanes, and other hydrocarbons in anaerobic bacteria. Biodegradation 11(1-2): 85-105.

6. Grifoll M, Selifonov SA, Chapman PJ (1994) Evidence for a novel pathway in the degradation of fluorene by Pseudomonas sp. strain F274. Appl Environ Microbiol 60(7): 2438-2449.

7. Nam K, Kukor JJ (2000) Combined ozonation and biodegradation for remediation of mixtures of polycyclic aromatic hydrocarbons in soil. Biodegradation 11(1): 1-9.

8. Van Hamme JD, Singh A, Ward OP (2003) Recent advances in petroleum microbiology. Microbiol Mol Biol Rev 67(4): 503-549.

9. Lovley DR (2000) Anaerobic benzene degradation. Biodegradation 11(2-3): 107-116.

10. Yoshikawa M, Zhang M, Toyota K (2017) Biodegradation of volatile Organic compounds and their effects on biodegradability under co-Existing conditions. Microbes Environ 32(3): 188-200.

11. Ghosal D, Ghosh S, Dutta TK, Ahn Y (2016) Current State of Knowledge in Microbial Degradation of Polycyclic Aromatic Hydrocarbons (PAHs): A Review. Front Microbiol 7: 1369.

12. Beller HR (2000) Metabolic indicators for detecting in situ anaerobic alkylbenzene degradation. Biodegradation 11(2-3): 125-139.

13. Patowary K, Patowary R, Kalita MC, Deka S (2016) Development of an Efficient Bacterial Consortium for the Potential Remediation of Hydrocarbons from Contaminated sites. Front Microbiol 7: 1092.

14. Karthikeyan S, Radhakrishnan M (2010) Characterization of proton production and consumption associated with microbial metabolism. BMC Biotechnol 10: 2. 


\section{Open Access Journal of Microbiology \& Biotechnology}

15. Zhang X, Sullivan ER, Young LY (2000) Evidence for aromatic ring reduction in the biodegradation pathway of carboxylated naphthalene by a sulfate reducing consortium. Biodegrad 11(2-3): 117-124.

16. Das N, Chandran P (2011) Microbial degradation of petroleum hydrocarbon contaminants: An Overview. Biotechnol Res Int.

17. Kamal MA, Klein P (2010) Estimation of BTEX in groundwater by using gas chromatography-mass spectrometry. Saudi J Biol Sci 17(3): 205-208.

18. van der Waals MJ, Atashgahi S, da Rocha UN, van der Zaan BM, Smidt H, et al. (2017) Benzene degradation in a denitrifying biofilm reactor: activity and microbial community composition. Appl Microbiol Biotechnol 101(12): 5175-5188.

19. Nikitin AN, Cheshyk IA, Gutseva GZ, Tankevich EA, Shintani M, et al. (2018) Impact of effective microorganisms on the transfer of radioactive cesium into lettuce and barley biomass. J Environ Rad 192: 491-497.

20. El-Shafei AA (2017) Impact of effective microorganisms compost on soil fertility and rice productivity and quality Misr J Ag Eng 25(3): 10671093.

21. Baker DB, Ray PM (1965) Relation between effects of auxin on cell wall synthesis and cell elongation. Plant Physiol 40(2): 360-368.
22. ID MM, Robert S (2018) The role of auxin in cell wall expansion. Int J Mol Sci 19(4): 951.

23. Mohite B (2013) Isolation and characterization of indole acetic acid (IAA) producing bacteria from rhizospheric soil and its effect on plant growth. J S Sci Plant Nutr 13.

24. Arkhipchenko IA, Shaposhnikov AI, Kravchenko LV (2006) Tryptophan concentration of animal wastes and organic fertilizers. Applied Soil Ecology 34(1): 62-64.

25. Wahyudi AT, Astuti RP, Widyawati A, Meryandini A, Nawangsih AA (2011) Characterization of Bacillus sp. strains isolated from rhizosphere of soybean plants for their use as potential plant growth for promoting Rhizobacteria. J Microb Antimicrob 3: 34-40.

26. Highton PJ, Hobbs DG (1971) Penicillin and Cell Wall Synthesis: a Study of Bacillus licheniformis by Electron Microscopy. J Bacteriol 106(2): 646-658.

27. Meléndez-Hevia E, Waddell TG, Cascante M (1996) The puzzle of the Krebs citric acid cycle: assembling the pieces of chemically feasible reactions, and opportunism in the design of metabolic pathways during evolution. J Mol Evol 43(3): 293-303.

28. Jajuee B, Margaritis A, Karamanev D, Bergougnou MA (2007) Kinetics of biodegradation of p-xylene and naphthalene and oxygen transfer in a novel airlift immobilized bioreactor. Biotechnol Bioeng 96(2): 232-243.

Chang HD, et al. Modulation of BTEX Bio-Remedial Activity by Molecular Triggering 